\title{
Yoğun Bakım Yatak Kullanım Verimliliğinin Pabon Lasso Modeli İle Değerlendirilmesi
}

\author{
Hatice ESEN ${ }^{1}$ ve Vahit YİĞITT ${ }^{2}$ \\ $\ddot{O}_{z}$
}

Hastanelerde sunulan sağlık hizmetleri, sağlık sistemlerinin en pahalı ve en önemli parçasıdır. Önemli maliyet girdileri oluşturmaktadır. Bu nedenle kıt olan kamu kaynaklarının etkin ve verimli kullanılması, atıl durumdaki kaynakların tespit edilmesi ve performans değerlendirmesinin yapılması önem arz etmektedir. Bu araştırmanın amac1, yoğun bakım ünitelerinin yatak kullanım verimliliği Pabon Lasso modeli (PLM) ile incelenmesidir. Araştırma retrospektif ve kesitsel olarak 2017 ve 2018 yılını kapsamaktadır. Araştırmaya bir eğitim araştırma hastanesinde hizmet veren tüm yoğun bakım üniteleri (YBÜ) dâhil edilmiştir. Araştırmada yoğun bakım ünitelerinin yatak kullanımı etkinliğini tespit edebilmek için yatak doluluk oranı (YDO), yatak devir hızı (YDH) ve ortalama kalış süresi (OKS) değissken olarak kullanılmıştır. Araştırmada kullanılan iki yıllık veriler Temel Sağlık İstatistikler Modülünden (TSIM) elde edilmiştir. Verilerin analizinde Macromedia ve MS Excel yazılımlarından yararlanılmıştır. Araştırmadan elde edilen bulguları sonucunda yoğun bakım ünitelerinin yatak doluluk oranı, yatak devir hızı ve ortalama kalış sürelerinde 2017 y1lına kıyasla 2018 yılında artış olduğu tespit edilmiştir. 2017 yılında yoğun bakımların \%30’u verimli bölgede iken, 2018 yılında \%20'sinin verimli bölgede olduğu saptanmıştır. 2017 yılında; düşük YDO ve YDH, uzun OKS'nin verimsiz olarak nitelendirilen 1. bölgede YBÜ’nin \%30, 2018 yıllnda ise bu bölgedeki YBÜ'sinin \%20'nin yer aldığı tespit edilmiştir. Hem 2017 hem de 2018 yllında bazı yoğun bakım ünitelerinin modelde değişken olarak kullanılan YDO, YDH ve OKS performans göstergeleri incelendiğinde; az biri açısında düşük performans gösterdiği saptanmıştır. Pabon Lasso modeli, yatak kullanım performansı hakkında hızlı ve anlamlı bilgiler vermektedir. Bu modelin yatak kullanım etkinliğinin ölçülmesinde diğer performans ölçüm yöntemlerinin yanı sıra kullanılması tavsiye edilmektedir.

Anabtar Kelimeler: Pabon Lasso Modeli, Yoğun Bakım Ünitesi, Yoğun Bakım Ünitesi Yatak Kullanım Verimliliği

\section{Evaluation of Intensive Care Bed Utilization Efficiency with Pabon Lasso Model}

\begin{abstract}
The health services provided in hospitals are the most expensive and the most important part of the health systems. It has significant cost inputs. Therefore, effective and efficient use of scarce public resources, identification of dormant resources and performance evaluation are important. The aim of this study is to investigate the efficiency of intensive care bed use with Pabon Lasso model (PLM). The study includes retrospective and cross-sectional studies in 2017 and 2018. This study includes all intensive care units (ICUs) in a training and research hospital. In order to determine the effectiveness of bed use in intensive care units, bed occupancy rate (BOR), bed turnover rate (BTR) and average length of stay (ALS) were used as variables. The two-year data used in the study is obtained from the Basic Health Statistics Module (TSIM). The data is analyzed applying Macromedia and MS Excel software. As a result of the findings obtained from the research, it is found that the bed occupancy rate, bed turnover rate and average length of stay of the intensive care units increased in 2018 compared to 2017. In 2017, low BOR and BTR, long ALS were found to be inefficient in the 1st region, $30 \%$ of the ICU and $20 \%$ of the ICU in this region in 2018. When the performance indicators of BOR, BTR and ALS used as variables in the model of some intensive care units in both 2017 and 2018 are examined; it has been found that it shows poor performance in terms of less than one. When the performance indicators used in some intensive care units as variables in the model were examined in both years, it was found that they showed poor performance in terms of at least one. The Pabon Lasso model provides fast and meaningful information about bearing performance. It is recommended that this model can be applied in addition to other performance measurement methods in measuring bed use efficiency.
\end{abstract}

Key Words: Pabon Lasso Model, Intensive Care Unit, Intensive Care Unit Bed Utilization Efficiency

\section{Atıf İçin / Please Cite As:}

Esen, H ve Yiğit, V. (2021). Yoğun bakım yatak kullanım verimliliğinin Pabon Lasso modeli ile değerlendirilmesi. Manas Sosyal Araștırmalar Dergisi, 10(2), 1138-1150.

Geliş Tarihi / Received Date: 19.12.2019

Kabul Tarihi / Accepted Date: 27.02.2021

\footnotetext{
${ }^{1}$ Dr. - Antalya Eğitim ve Araştırma Hastanesi, hatice.esen@gmail.com

(iD) ORCID: 0000-0003-1164-9086

2 Doç. Dr. - Süleyman Demirel Üniversitesi İ̈BF Fakültesi, yigitv@hotmail.com

(iD) ORCID: 0000-0002-9805-8504
} 


\section{Giriş}

Hastanelerin, küresel rekabetin üstesinden gelebilmesi için tüm sektörlerde olduğu gibi çevresel değişikliklere uyum sağlaması, yeni hizmetler geliştirmesi, yenilikçi fikirlere öncülük etmesi ve modern teknolojiye eş zamanlı uyum sağlaması gerekmektedir (Evans., Edejer, Lauer, Frenk ve Murray, 2001, s. 293). Bu uyumun ölçülmesi ve özellikle kamuya ait sağlık kurumlarında sorunların ortadan kaldırılması için, performans ölçümleri yapılarak daha verimli hizmet üretmenin çözüm yolları aranmaya başlanmışır (Beylik ve Pekcan, 2008, s. 121). Hastaneler, verimli ve etkin olabilmek için maliyetleri düşürmeli aynı zamanda kaliteli sağlık hizmetleri sunmalıdır. Hastanelerde verimsizliğe yol açan temel nedenler; personel, malzeme, ilaç, sağlık teknolojisi, yatak, bina gibi girdilerin verimli kullanılmamasıdır. Hastanelerde, kaynak yönetiminde doğru planlama yapılmadığında, girdiler kaynak israfı nedeni olabilir (Yiğit, 2019). Kaynakların etkin ve verimli kullanılması sağlık sistemlerinin temel amaçlarından birisidir. Hastaneler, sağlık hizmetlerinin topluma doğrudan ulaştırllmasından sorumlu en önemli kurumlar olup toplam sağlık harcamalarının büyük bir bölümünü kullanmaktadır (Linna, Häkkinen ve Magnussen 2006, s. 269; Caballer-Tarazona vd., 2010, s. 1095). Türkiye'de TUIK (2017) sağl1k harcamalar1 verilerine göre; sağlık sektörü tarafindan yapılan harcamaların yaklaşık \%50'si hastaneler tarafindan gerçekleştirilmiştir (TUIK, 2017). Bu nedenle, hastane performansının izlenmesi ve gerekli önlemlerin alınması, sağlık sisteminin performansı üzerinde önemli bir etkiye sahip olacaktır. Bu bağlamda hastanelerde, etkin, verimli ve kaliteli hizmet sunumunda, sağlık sistemlerinin performansını izlemek, ölçmek ve yönetmek için performans göstergeleri kullanılması kaçınılmazdır (Khalifa ve Khalid, 2015,s.459). Hastaneler, dinamik bir ortamda farklı ve özellikli birimlerden oluşan, karmaşık yapıya sahip, kesintisiz hizmet sunan kurumlardır (Ağırbaş, 2019, s. 16). Karmaşık ve multidisipliner hasta bakımı gerektiren özellikli birimlerden birisi de YBÜ'dir. YBÜ; hasta bakımı ve tedavisi açısından özellikli, ileri teknolojiye sahip cihazlarla donatılmış, hastaların 24 saat yaşamsal göstergelerinin izlendiği, diğger birimlere göre daha yüksek ölüm oranına sahip kliniklerdir. YBÜ, kaynakların verimli kullanımının yanı sıra en iyi hasta bakım sonucu sağlamayı amaçlanmaktadır (Anushiravani ve Masoompour, 2017, s. 163). Bu birimlerde hasta tedavi ve bakım maliyeti de oldukça yüksek olup, birçok hastanede toplam harcamalarının \%25-\%40'nı oluşturmaktadır. Bu nedenle YBÜ performans değerlendirmesi yapılarak etkinliğinin artırılmasıla hastane maliyetinin azaltılması hedeflenmektedir. YBÜ'sinin verimliliğinin artırılmas1 stratejileri arasında klinik uygunluk, uygun kalış süresi gibi göstergeler de yer almaktadır (Cooper, Sirio, Rotondi, Shepardson ve Rosenthal 2016, s. 399). Hastane maliyetlerini etkileyen temel nedenler arasinda; kapasite kullanımı, hastane büyüklügü, hizmet kalitesi, hasta sevk zincirinde yer alan kademe, hizmet sunulan nüfus yoğunluğu ve epidemiyolojik yapisı, hastane imajı, sağlık profesyonelleri, hastanenin makine-teçhizat yapısı, finansal kaynak, gereksiz cerrahi girişimler ve dışardan hizmet alımı gelmektedir (Yigit ve Ağırbaş 2004, s. 142; Arslan, Önder, Kayalı, Keskin ve Yiğit 2015, s. 40). Sağlik hizmeti sunan kurumlarda verimliliğin artırlması; verimsizlik nedenlerin tespit edilmesi, denetlenebilir ve iyileştirilebilir olması ile gerçekleştirilebilir (Arslan vd., 2015, s.40). Mevcut hasta yatağ1 ile daha fazla hastaya daha ekonomik, sağlık hizmeti sunulabilmesi için hastane yöneticisi gelişen teknoloji ve güncel bilimsel veriler ışığında çağdaş, modern ve bilimsel yönetim modelleri kullanılmalıdır (Aksaraylı, Kıdak ve Güneş, 2009, s. 4).

Bu araştırmanın amacı, Pabon Lasso Modeli ile Antalya Eğitim ve Araştırma Hastanesi'nde hizmet veren yoğun bakım ünitelerinin 2017 ve 2018 yıllarına ait yatak kullanım performans düzeylerini tespit etmektir.

\section{Kavramsal Çerçeve}

Verimlilik, hizmet üretim miktarı ile bunların üretilmesinde kullanılan girdiler arasındaki ilişkiyi yani amaçların en az kaynak kullanılarak gerçekleştirilmesi olarak tanımlanmaktadır (SAS, 2015, s. 10). Genel olarak verimlilik, hizmet ve/veya mal üretmek için gereken girdilere göre çıktıları ölçmektedir (Özcan, 2009, s. 206). Verimliliğin tanımında, üç temel amaç açıklanmaktadır. Bunlar; aynı çıtıların elde edilmesi için girdileri azaltmak, aynı girdileri kullanarak daha fazla çıktı elde etmek, son olarak kaynakların artması karşılığında orantılı olarak daha fazla çıktı elde etmektir (Choi ve Jung 2017, s. 2).

Hastaneler; araştırma, eğitim, rehabilitasyon, tanı, tedavi ve bakım süreçlerini kapsayan klinik ve yönetim hedeflerini başararak hastalarına daha iyi sağlık hizmeti sunmayı amaçlamaktadır (Gollhofer, 2015, s. 36-37). Hastaneler için performans ölçüm göstergelerini çeşitli özellikler temel alınarak sınıflandırmak mümkündür (Beylik ve Pekcan 2008, s. 122). Hastanelerin performans göstergeleri arasında yatakların 
etkin kullanılması, insan kaynaklarının etkin kullanılması, poliklinik sayısının artırılması, taburcu edilen hasta oranın yüksek olması ve mali göstergeler yer almaktadır Bu göstergeler aracilığı ile sağlık kurumları birbirleriyle kıyaslanmış olacaktır (Tengilimoğlu, Işık ve Akbolat 2012, s. 409).

Hastanelerin performans değerlendirmesinde çeşitli yöntemler kullanılmaktadır. Bu yöntemler genellikle oran analizi, parametrik ve parametrik olmayan yöntemler kullanılmaktadır (Özkan, Başlıgil ve Şahin, 2011, s. 4; Azreena, Juni ve Rosliza, 2018, s. 18). Hastane yatak kapasite kullanımı ile ilgili kararlarının alınmasinda hedeflenen yatak doluluk seviyeleri esas alınmaktadır ve kullanılan yatak doluluk oranı hedefinin \%85 olduğu bilinmektedir. Yatak doluluk hedefleri, maliyetleri kontrol altına almak için hastane yataklarının arzını kontrol etmek amaciyla yapılmaktadır (Gree, 2002, s. 401). Hastanelerde mevcut yatak dağılımı ve tahmini yatak ihtiyaçları, temel düzeyde ortalamalar ve oranlar kullanılarak hesaplanmaktadır (Harper ve Shahani, 2002, s. 12). Hastane kapasitesi belirlenirken bazı göstergeler esas alınmaktadır. Dünya Sağlık Örgütü (DSÖ) tarafından yapılan araştırmaya göre; kapasite kullanım oranı, ortalama kalış süresi, toplam hasta sayısı, yatak işgal oranı gibi göstergelerin daha sık kullanıldığı ifade edilmiştir (Güzel, 1996, s.2-3). Hastane yatak kapasite kullanımında sıklıkla Pabon Lasso Modeli(PLM) kullanılmaktadır. Türkiye'de sağlık kurumlarının performans değerlendirmesinde sinırlı sayıda PLM'nin kullanıldığ1 çalışma yapılmıştır (Boz, Yılmaz ve Şenel, 2018; Çalışkan 2016; Ekiyor, 2015; Yiğit ve Kumru, 2016; Yiğit 2017; Yıldız, 2017; Yiğit ve Esen, 2017). Hastanelerde yatak kullanım performansının değerlendirilmesi maliyetlerin izlenmesinde önemli etkisi olan göstergelerden biri olarak kabul edilmektedir (Yiğit ve Ağırbaş, 2004 ,s. 143). Hastane yataklarının en uygun kapasitede kullanılması birim maliyetleri azaltmakta ve hastaların kısa sürede sağlık hizmeti almalarını sağlamaktadır (Aksaraylı, Kıdak ve Güneş, 2009 , s. 4). Hastanelerde mevcut hasta yatağının etkin ve verimli kullanılması ile daha fazla hastaya sağlık hizmeti sunulması hastane yönetiminin bilimsel yönetim metodunu kullanmasıyla sağlanabilir (Yiğit ve Ağırbaş, 2004, s. 142). Türkiye'de sağlık hizmeti sunumu açısından en büyük paya sahip olan kamu hastaneleri kaynaklarını etkin ve verimli kullanmayı temel bir politika haline getirmiştir (Çakmak, Öktem ve Ömürgönülşen, 2009, s. 4). Bu nedenle sözleşmeli yönetici performans değerlendirmesinde genel yatak doluluk oranı performans göstergesi olarak izlenmektedir. Bu performans kriterine göre genel hastane YDO hedef değeri \%70-85 olarak belirlenmiştir (SB, 2019).

\section{Pabon Lasso Modeli (PLM)}

Hastanelerin performanslarının değerlendirilmesinde kullanışlı olan PLM, hastanelerin göreceli performansının belirlenmesinde kullanılmak üzere Hipolito Pabón Lasso tarafından (1986) geliştirilmiş olup, performans ölçümünde; YDO, OKS ve YDH göstergeleri kullanılmaktadır (Lasso, 1986, s. 341). Yapılan çalışmalarda modelin hastane veya kliniklerin yatak kullanım performanslarını kıyaslayarak verimsizlik alanlarını belirlemek ve düşük performans gösteren hastane veya klinikleri tespit etmek için kullanılan en iyi performans modellerden biri olduğu ifade edilmektedir (Aeenparast, Farzadi, Maftoon, Zandian ve Yazdeli 2015, s. 143; Davoud vd., 2014, s. 1). Bu model, ayn1 anda YDO, YDH ve OKS olmak üzere üç önemli hastane performans göstergesini dikkate alarak kapasite kullanımını ölçen ve kullanım kolaylığına sahip bir yöntemdir (Emamgholipour, Afkar, Eskandari, Tavakkoli, 2015, s. 177; Tripathi, Kumar, Sharma ve Agarwal, 2016, s. 64). Hastane maliyetlerinin büyük bir bölümü sabit olduğu için, çok yüksek YDH ve YDO taburcu olan hasta başına maliyeti düşürmekte ve kaynakların verimli kullanılmasını sağlamaktadır (Vella vd., 2017, s. 460). PLM'de kullanılan değişkenler aşağıda kısaca açıklanmıştır.

Yatak Devir Hızı (YDH): Hastanenin kaynaklarının nasıl kullanıldığının ölçümüdür (Rahman, Tumpa, Ali ve Kumar, 2018, s. 168). Bir yatağın ilgili dönem (ay, yll) içerisinde hastalar tarafindan kaç kez kullanıldığını gösteren bir performans göstergesidir. YDH aşağıdaki formüle göre hesaplanır (SB, 2016). Sözleşmeli yönetici performans değerlendirme kriterlerine göre; sağlık tesislerinin yatak kapasitesinin doğru ve verimli kullanımını sağlamak için hastane YDH \% 70-85 arasında olması gerekmektedir (SB, 2019).

Yatak Devir Hızı $=\frac{\text { Taburcu olan hasta sayısl (ölen dahil) }}{\text { Yatak sayısl }}$

Yatak Doluluk Oranı (YDO): Belirli bir süre içerisinde hastane yataklarının ne oranda kullanıldığını gösteren bir performans göstergesidir. YDO hesaplanmasında aşağıdaki formül kullanılmaktadır (SB, 2016). Hastane performansının bir göstergesi olan YDO, hastalara uygun sağlık bakım hizmetinin verildiğinin ve iyi çalıştı̆̆ının bir göstergesi olup \%85'in üzerinde olması önerilmektedir (Keegan, 2010, s. 291). Sözleşmeli yönetici performans değerlendirme kriterlerine göre; sağlık tesislerinin yatak kapasitesinin 
doğru ve verimli kullanımını sağlamak için hastane YDH \%70-85 arasında olması gerekmektedir (SB, 2019).

Yatak Doluluk Oranı $=\frac{\text { Toplam yatılan gün saylsl }}{\text { Yatak Sayısı } \times 365} \times 100$

Ortalama Kalış Süresi (OKS): Hastaların tedavi ve bakım amaçlı hastane içerisinde bulundukları süreyi belirleyen önemli bir göstergedir. Yani ortalama kalış süresi, taburcu olan bir hastanın hastanede ortalama kaç gün kaldığını gösteren bir ölçüt olarak tanımlanabilmektedir (Sümbüloğlu, 1990). OKS, hastanın hastalığına özgü koşullar nedeniyle değişebilmektedir. Diğer tüm değişkenler sabit kalırsa, daha kısa bir süre kalmak taburcu olma maliyetini düşürebilir (Rahman, Tumpa, Ali ve Kumar 2018, s. 1). OKS aşağıda yer alan formüle göre hesaplanmaktadır (SB, 2016).

Ortalama KalışS Süresi $=\frac{\text { Yatılan Gün Sayısı }}{\text { Taburcu ve Ölen Hasta Sayısı }}$

PLM; x ekseninde yatak doluluk oranı, y eksenin de ise yatak devir hızının olduğu dört bölgeden oluşur (Lasso, 1986, s. 341). Bu model yatak kullanımı ile ilgili düşük performans gösteren klinikleri belirleyebildiği ve kliniklerin verimsizliklerini düzeltebilecekleri alanları grafiksel olarak gösterebilen bir yöntemdir (Tripathi vd., 2016, s. 69). PLM Şekil 1'de gösterilmiş ve dört bölgesi aşağılda kısaca açıklanmışır (Davoud vd., 2014, s. 6).

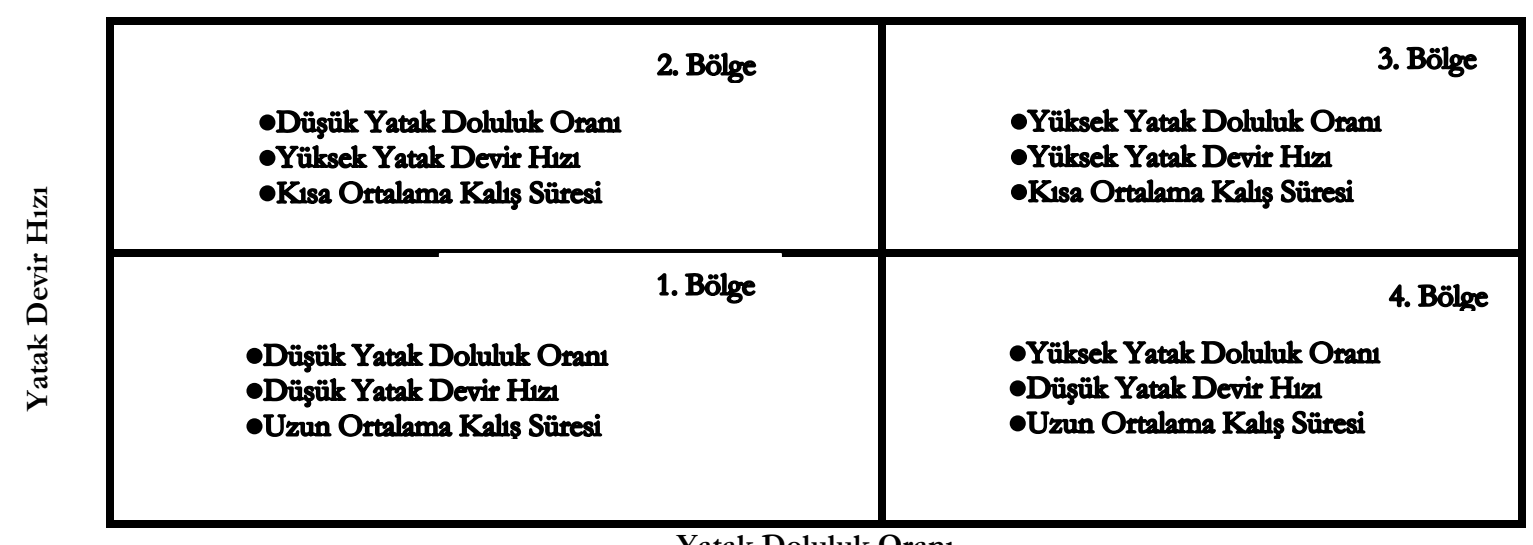

Şekil 1. Pabon Lasso Modeli (Kaynak: Davoud vd, 2014, s. 3)

1. Bölge: Bu bölgede bulunan hastaneler veya klinikler YDH ve YDO düşük olduğu için verimsiz olarak değerlendirilir. Bu bölgede en az hastane veya kliniğin olması beklenir. Birinci bölgede yer alan hastane veya kliniklerin kapasite arzı talebin üzerindedir, bir başka değişle yatak kapasitesi ihtiyacı aşmış durumdadır. Bu bölgede bulunan hastaneler daha çok ayaktan sağlık hizmeti sunan veya hastaları genellikle farklı kurumlara sevk eden ağız ve diş sağllğı merkezi gibi hastaneler olduğu söylenebilir (Tripathi, Kumar, Sharma ve Agarwal, 2016, s. 70).

2. Bölge: Bu bölgede yer alan hastane veya kliniklerin YDH yüksek iken, YDO düşük ve OKS oldukça kısadır. YDO'nın düşük olması yine arzın talebi aşması bir başka deyişle gereğinden fazla yatak olduğu varsayılmaktadır. Yatak devir hızının yüksek olması ise yatakların daha çok gözlem amaçlı kullanıldığının göstergesidir (Davoud vd., 2014, s. 6).

3. Bölge: Bu bölgede yer alan hastane veya klinikler yüksek YDH ve yüksek YDO'na sahip olduğu için verimli yani etkin performansa sahip olarak nitelendirilmektedir. Bu bölgede yer alan hastane ve kliniklerde gereksiz uzun kalış süresi ve atıl yatakların olmadığı söylenebilir. Bu nedenle hastane veya kliniklerin bu bölgede yer alması istenir söylenebilir (Tripathi, Kumar, Sharma ve Agarwal, 2016, s. 70).

4. Bölge: Bu bölgede yer alan hastane veya kliniklerde OKS uzun, YDH düşük ve YDO yüksektir. $\mathrm{Bu}$ bölgede bulunan hastane veya kliniklerde gereksiz yere uzun süreli hastalara hizmet sunulmaktadır. $\mathrm{Bu}$ bölgede yer alan hastane veya klinikler genellikle; akıl ve ruh sağlığ1 hastalıkları, fizik tedavi ve rehabilitasyon hastalıkları, göğüs hastalıkları, palyatif kliniği ve nöroloji kliniği gibi uzun dönem yatış 
gerektiren kronik hastalıların tedavisi yapılmaktadır (Davoud et al., 2014, s. 6; Bahadori, Sadeghifar, Hamouzadeh, Hakimzadeh ve Nejati, 2011, s. 176)

Her performans değerlendirme yönteminin avantajları ve sınırlılıkları bulunmaktadır. PLM, hastane yöneticilerine yönetmiş oldukları hastanenin durumunu diğer hastanelerle karşılaştırmasına yardımc1 olmakta ve hastane performansının değerlendirmesinde kolaylık sağlamaktadır. Bununla birlikte sadece yatak performansının dikkate alınmasından dolayı sınırlı olarak kabul edilmiştir (Aeenparast, Farzadi, Maftoon, Zandian ve Yazdeli 2015, s. 144). PLM, hastane veya kliniklerin yatak kullanım performansinın değerlendirilmesinde önerilen oldukça basit ve kullanışlı modellerden birisidir. Sağlık sistemindeki kaynak yetersizliği ve ayrıca hastanelerin belirli kaynaklara daha fazla ihtiyaç duyması, verimlilik ve mevcut kaynakların uygun şekilde kullanılmasına daha fazla dikkat edilmesinin en önemli nedenlerinden biridir

\section{Yöntem}

\section{Çalışmanın Amacı}

$\mathrm{Bu}$ araștırmanın amacı, Pabon Lasso Modeli ile Antalya Eğitim ve Araștırma Hastanesi'nde hizmet veren yoğun bakım ünitelerinin 2017 ve 2018 yllarına ait yatak kullanım performans düzeylerini tespit etmektir.

\section{Evren - Örneklem}

Araştırmanın evrenini bir eğitim ve araştırma hastanesinde hizmet veren cerrahi ve dâhili yoğun bakım üniteleri oluşturmaktadır. Araştırma kapsamına, Anestezi ve Reanimasyon YBÜ, Cerrahi YBÜ, Çocuk YBÜ, Dâhili YBÜ, Genel YBÜ 1, Genel YBÜ 2, Koroner YBÜ, KVC YBÜ, Nöroloji YBÜ ve Yeni Doğan YBÜ alınmıştır. Araştırmada örneklem çekilmemiş tüm yoğun bakım üniteleri dâhil edilmiştir.

\section{Veri Toplama Araçları}

Araştırmada hastanelerin yatak kullanımı etkinliğini tespit edebilmek için PLM kullanılmıştır. Modelde değişken olarak hastane performans göstergesi olan yatak doluluk oranı, yatak devir hızı ve ortalama kalıs süresi kullanılmıştır. Araştırma verileri Temel Sağlık İstatistikleri Modülünden (TSİM) elde edilmiştir. Araştırma kapsamında hastane yönetiminden yazılı izin alınmıştır.

\section{Verilerin Analizi}

Bu araştırma, 2017-2018 yılları arasında yoğun bakım ünitelerinde yatak kullanım kapasitesini tespit eden kesitsel ve retrospektif bir araştırmadır. Araştırma, bir eğitim ve araştırma hastanesine ait 10 adet yoğun bakım ünitesini kapsamaktadır. PLM performans değerlendirme modelinin haritasını çıkarmak için YDO, YDH ve OKS olarak üç gösterge gereklidir. Veri analizi için MS Excel, PLM grafiğinin oluşturulmasında Macromedia yazılımından yararlanılmıştır. Veri analizi, tanımlayıcı istatistiksel yöntemler kullanılarak yapilmıştır.

\section{Araştırmanın Sınırlılığı}

Araştırmanın yapıldığı yoğun bakım üniteleri yalnızca bir eğitim ve araştırma hastanesinde hizmet sunan birimlerden oluşmaktadır. Bu araştırmadan elde edilen veriler sadece araştırmanın yapıldığı yoğun bakım üniteleri için genellenebilir.

\section{Bulgular}

Eğitim ve Araştırma Hastanesi’nde hizmet veren 10 adet yoğun bakım ünitesinin 2017 ve 2018 yılı yatak kapasite kullanımı ile ilgili performans göstergeleri Tablo 1'de sunulmuştur. Buna göre araştırma kapsamında kullanılan YBÜ’nin 2017 yılı ortalama; YDO \% 74,10, OKS 5,99 gün ve YDH 69,98 olarak tespit edilmiştir. 2018 verileri incelendiğinde ortalama YDO \% 82,04, OKS 6,31 gün ve YDH 80,68 olduğu belirlenmiştir. 2017 yılında; YDO bakımından en yüksek değere sahip yoğun bakım Cerrahi YBÜ $(\% 98,80)$, en düşük değere sahip yoğun bakım ise genel YBÜ $1(\% 50,70)$ olarak tespit edilmiştir. OKS performans göstergesi bakımından; en yüksek değere sahip nöroloji YBÜ (15,29 gün), en düşük değere sahip KVC YBÜ (2,03 gün) ve YDH göstergesi açısından ise en yüksek değere sahip koroner YBÜ $(148,95)$, en düşük değere sahip yeni doğan YBÜ $(15,28)$ olarak bulunmuştur. 2018 yllında; YDO bakımından en yüksek değere sahip yoğun bakım cerrahi YBÜ $(\% 99,60)$, en düşük değere sahip yoğun bakım ise yeni doğan YBÜ (\%56,50), OKS performans göstergesi bakımından en yüksek değere sahip nöroloji YBÜ (17,21 gün), en düşük değere sahip KVC YBÜ (1,74 gün) ve YDH göstergesi açısından ise 
en yüksek değere sahip Dahili YBÜ (154,50), en düşük değere sahip yeni doğan YBÜ $(17,33)$ olarak tespit edilmiştir (Tablo 1).

Tablo 1. Yoğun Bakım Ünitelerinin Yatak. Kullanım Performans Göstergeleri

\begin{tabular}{|c|c|c|c|c|c|c|c|c|}
\hline \multirow{2}{*}{ Yoğun Bakım Adı } & \multirow{2}{*}{$\begin{array}{l}\text { Yoğun } \\
\text { Bakım } \\
\text { Seviyesi }\end{array}$} & \multirow{2}{*}{$\begin{array}{l}\text { Yatak } \\
\text { Sayis1 }\end{array}$} & \multicolumn{3}{|c|}{2017} & \multicolumn{3}{|c|}{2018} \\
\hline & & & OKS & YDH & YDO & OKS & YDH & YDO \\
\hline YBÜ1: Anestezi ve Reanimasyon YBÜ & 3 & 16 & 5,49 & 73,06 & 98,70 & 6,37 & 62,19 & 95,90 \\
\hline YBÜ2: Cerrahi YBÜ & 3 & 14 & 5,14 & 75,57 & 98,80 & 5,72 & 75,57 & 99,60 \\
\hline YBÜ 3: Çocuk YBÜ & 3 & 12 & 3,61 & 58,17 & 62,80 & 4,59 & 64,50 & 82,70 \\
\hline YBÜ 4: Dahili YBÜ & 2 & 4 & 3,60 & 74,75 & 73,70 & 2,66 & 154,50 & 98,50 \\
\hline YBÜ 5: Genel YBÜ 1 & 3 & 30 & 6,92 & 23,33 & 50,70 & 6,28 & 47,87 & 80,30 \\
\hline YBÜ 6: Genel YBÜ 2 & 1 & 4 & 2,71 & 82,50 & 52,90 & 3,29 & 92,50 & 66,30 \\
\hline YBÜ 7: Koroner YBÜ & 2 & 20 & 2,33 & 148,95 & 93,70 & 2,50 & 139,75 & 93,30 \\
\hline YBÜ 8: KVC YBÜ & 3 & 7 & 2,03 & 125,43 & 65,40 & 1,74 & 132,14 & 61,20 \\
\hline YBÜ 9: Nöroloji YBÜ & 3 & 12 & 15,29 & 22,75 & 89,70 & 17,21 & 20,50 & 86,10 \\
\hline YBÜ 10: Yeni Doğan YBÜ & 3 & 40 & 12,75 & 15,28 & 54,60 & 12,70 & 17,33 & 56,50 \\
\hline Ortalama & & & 5,99 & 69,98 & 74,10 & 6,31 & 80,68 & 82,04 \\
\hline Std. Sapma & & & 4,54 & 43,55 & 19,50 & 4,95 & 48,38 & 15,82 \\
\hline Minimum & & & 2,03 & 15,28 & 50,70 & 1,74 & 17,33 & 56,50 \\
\hline Maksimim & & & 15,29 & 148,95 & 98,80 & 17,21 & 154,50 & 99,60 \\
\hline
\end{tabular}

Tablo 2'de dahili ve cerrahi YBÜ'lerinin yatak performans değerleri sunulmuştur. 2017 verileri incelendiğinde; dahili YBÜ'sinde YDO 60,20 iken cerrahi YBÜ'de 92,45'dir. Her iki yoğun bakımda ortalama kalıss süreleri birbirine yakındır. 2018 verilerine göre; dahili YBÜ’de YDO 75,62 iken cerrahi YBÜ'de YDO 90,70, dahili yoğun bakım OKS 5,1 gün iken cerrahi yoğun bakım OKS 4,6 gün olduğu görülmektedir. YDH yıllara göre; dahili yoğun bakımda 56,48 (2017) ve 56,82 (2018) cerrahi yoğun bakımda ise 83,92 (2017) ve 80,49 (2018) bulunmuştur.

Tablo 2. Dabili ve Cerrabi Yoğgn Bakım Ünitelerinin Yatak Kullanm Performans Göstergeleri

\begin{tabular}{ccccc}
\hline & & 2017 & & 2018 \\
\hline OKS & Dahili YBÜ & Cerrahi YBÜ & Dahili YBÜ & Cerrahi YBÜ \\
YDH & 4,74 & 4,37 & 5,10 & 4,60 \\
YDO & 56,48 & 83,92 & 56,82 & 80,49 \\
\hline
\end{tabular}

YBÜ'lerinin, 2017 yılı yatak performans ortalamasına göre PLM'inde bölge dağllımı Sekil 2'de verilmiştir. Buna göre; yüksek yatak doluluk oranı, yüksek yatak devir hızı ve kısa hasta yatış süresine sahip olan ve 3. bölgede yer alan YBÜ'leri verimli olarak değerlendirilmektedir. Bu kapsamda verimli alan olan üçüncü bölgede; YBÜ1, YBÜ 2, YBÜ7 olduğu tespit edilmiştir. PLM'ne göre yoğun bakımların \%30'unun tamamen verimli olduğunu saptanmıştır. Birinci bölgede; düşük yatak doluluk oranı, düşük yatak devir hızı, uzun hasta yatış süresine yoğun bakımlar yer almakta ve verimsiz olarak değerlendirilmektedir. $\mathrm{Bu}$ kapsamda verimsiz alan olan birinci bölgede; YB3, YB5 ve YB10 olduğu tespit edilmiştir. PLM'ne göre yoğun bakımların \%30'unun tamamen verimsiz olduğunu saptanmıştır. İkinci ve dördüncü bölgede ise düşük YDO, yüksek YDH kısa OKS veya yüksek YDO, düşük YDH ve uzun OKS sahip, PLM'ne göre verimli de olmayan YBÜ \%40'ını oluşturmaktadır. 


\section{Ortalama Kalış Süresi (OKS)}

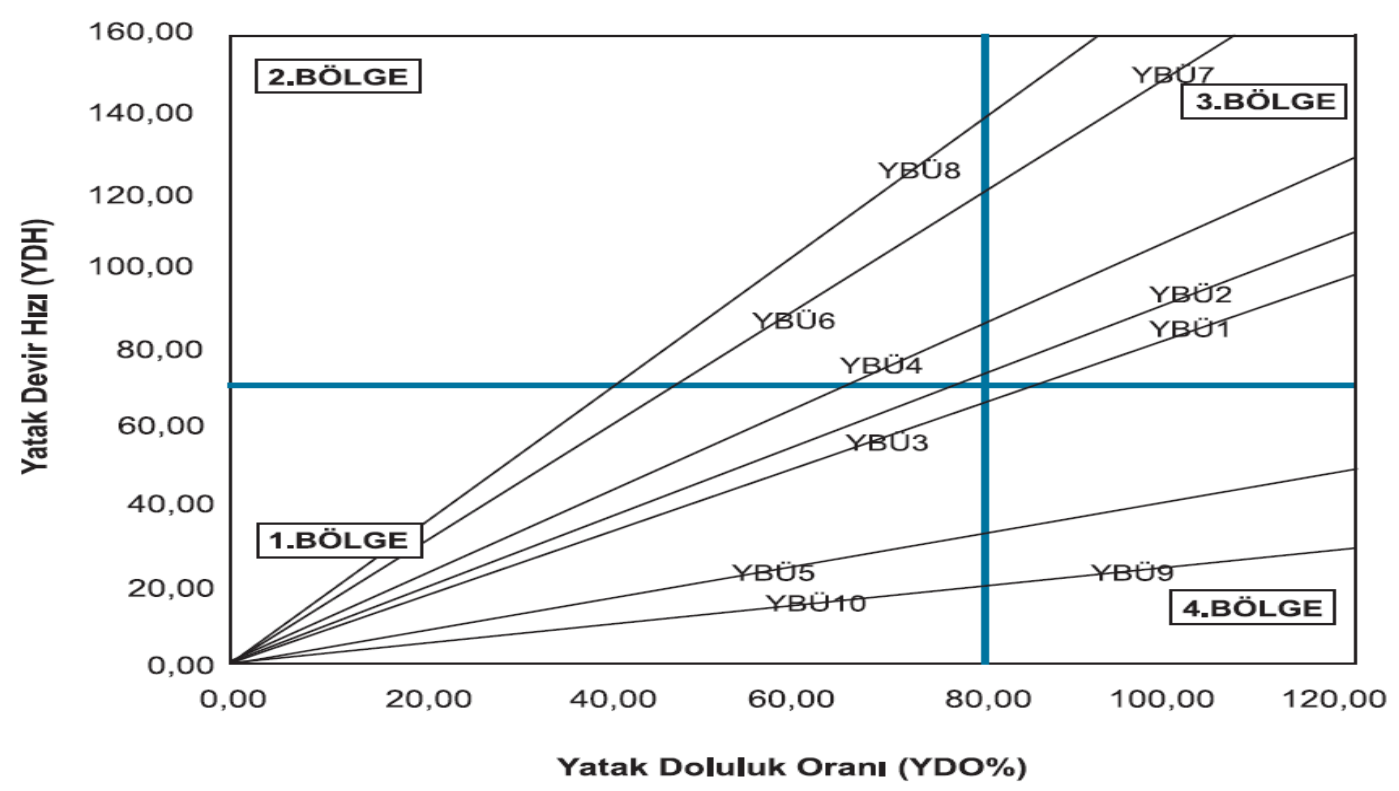

Şekil 2. Pabon Lasso Modeline Göre Yoğun Bakım Ünitelerinin Performansı (2017 Yil)

YBÜ'lerinin, 2018 yllı yatak performans ortalamasına göre PLM'inde bölge dağılımı Şekil 3'te verilmiştir. Buna göre; yüksek yatak doluluk oranı, yüksek yatak devir hızı ve kısa hasta yatış süresine sahip olan üçüncü bölgede yer alan YBÜ'leri; YB4 ve YB7'dir. PLM'ne göre yoğun bakımların \%20'sinin tamamen verimli olduğunu saptanmıştır. Düşük yatak doluluk oranı, düşük yatak devir hızı, uzun hasta yatış süresine sahip klinikler verimsiz olarak değerlendirilmektedir. Bu kapsamda verimsiz alan olan birinci bölgede; YB5 ve YB 10 olduğu tespit edilmiştir. PLM'ne göre, YBÜ'lerinin \%20'sinin tamamen verimsiz olduğunu saptanmıștır. PLM'ne göre verimli olmayan ikinci ve dördüncü bölgede yer alan diğer YBÜ’leri \%60’tır.

\section{Ortalama Kalış Süresi (OKS)}

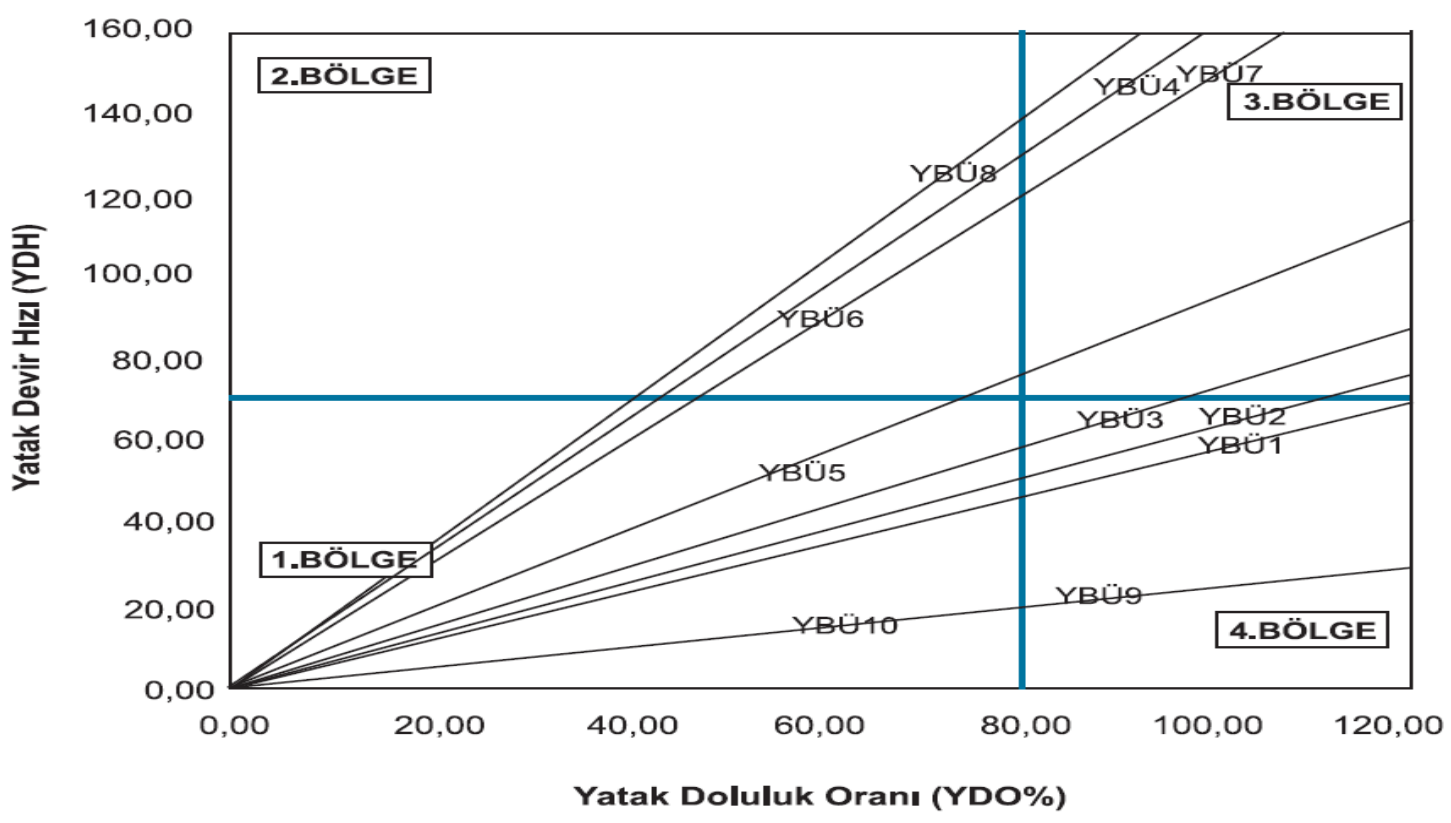

Şekil 3. Pabon Lasso Modeline Göre Yoğun Bakım Ünitelerinin Performansı (2018 Yıli) 
Tablo 3'te araştırmaya dâhil edilen yoğun bakımların yer aldığı bölgelerin dağılımı gösterilmiștir. Bu veriler değerlendirildiğinde 2017 yllında 3 adet, 2018 yllinda ise 2 adet YBÜ 3. bölgede yer almıştır. Verimsiz olarak değerlendirilen 1. bölgede ise 2017 yllında 3 ünite yer alırken 2018 yllında 2 ünitenin bu bölgede olduğu saptanmıştır.

Tablo 3. Yoğun Bakımlarn Bölgeleri Göre Dağglmı

\begin{tabular}{|c|c|c|c|}
\hline Yoğun Bakım Adı & Yoğun Bakım Seviyesi & 2017 PLM Bölgesi & 2018 PLM Bölgesi \\
\hline YBÜ 1 & 3. BASAMAK & 3. Bölge & 4.Bölge \\
\hline YBÜ 2 & 3. BASAMAK & 3. Bölge & 4. Bölge \\
\hline YBÜ 3 & 3. BASAMAK & 1. Bölge & 4.Bölge \\
\hline YBÜ 4 & 2. BASAMAK & 2. Bölge & 3.Bölge \\
\hline YBÜ 5 & 3. BASAMAK & 1.Bölge & 1.Bölge \\
\hline YBÜ 6 & 1.BASAMAK & 2.Bölge & 2.Bölge \\
\hline YBÜ 7 & 2. BASAMAK & 3. Bölge & 3. Bölge \\
\hline YBÜ 8 & 3. BASAMAK & 2.Bölge & 2.Bölge \\
\hline YBÜ 9 & 3. BASAMAK & 4.Bölge & 4.Bölge \\
\hline YBÜ 10 & 3. BASAMAK & 1.Bölge & 1.Bölge \\
\hline
\end{tabular}

\section{Tartışma, Sonuç ve Öneriler}

Araştırmanın bu bölümünde Pabon Lasso modeline göre yoğun bakımların yatak kullanım verimlilik düzeylerine ait bulgular literatür de yer alan sonuçlar ile karşılaştırlmıştır. Performans değerlendirmesinde ve maliyetlerin izlenmesinde yatak kapasitesi kullanım oranı genel kalite göstergelerinin başında gelmektedir. Hastanelerde yoğun bakım yatak potansiyelinin ne ölçüde kullanıldığı oldukça önemlidir. Düşük YDO, personel maliyetlerinin verilen hizmete göre yüksek kalmasına ve mevcut potansiyelin verimli kullanılamamasına yol açmaktadır. Hollanda Yoğun Bakım Derneği (NVIC) YDO için \%80 değerini üst eşik olarak tanımlarken (Veer vd., 2011, s. 3) Türkiye'de Sağlık Bakanlığı verimlilik karnesi gösterge kartlarında kabul edilebilir yoğun bakım YDO ise \%85 olarak belirlenmiştir (TKHK, 2016).

2017 yılı Kamu Hastaneleri Rapor Bülteninde; Türkiye'de erişkin yoğun bakım YDO \%79,3, yeni doğan yoğun bakın YDO \%68,5 ve çocuk yoğun bakım YDO \%75,8 olarak açılanmıştır. Tüm YBÜ'nin ortalama YDO \%76,3'tür. Bu durum yoğun bakım yataklarının verimli olarak kullanıldığının bir göstergesidir (SB, 2017). Bu araştırmada yer alan yoğun bakımların yatak doluluk oranlarının ortalaması 2017 yllında \%74,10 iken, 2018 yllında \%82,04 olarak bulunmuştur. Araştırmada YBÜ yatak kullanımı 2017 yllında Türkiye ortalamasına göre düşük, 2018 yllında ise ortalamanın üzerindedir. Araştırmada yer alan dâhili yoğun bakımların yatak doluluk oranı 2017 yllında \%60,20 iken 2018 yllında \%75,62 olarak bulunmuştur. Türkiye'deki yoğun bakım verileri ile kıyaslandığında; cerrahi YBÜ’sini \%098,80 (2017) ve $\% 99,60$ (2018) YDO ile ortalamanın üzerinde olduğu saptanmıştır. Çocuk YBÜ verileri değerlendirildiğinde; 2017 yllında \%62,80 YDO ile Türkiye ortalamasına göre düşük, 2018 yllında\%82,70 YDO ile ortalamanın üzerindedir. Yeni doğan YBÜ, YDO (\%54,60/2017, \%56,50/2018 ylli) her iki yılda da Türkiye ortalamasının altındadır.

TKHK (2015) tarafindan yapılan yoğun bakım araştırmaları raporunda; hastaların yoğun bakım ünitelerinde ortalama kalış süresin 7,09 gün olduğu belirtilmiştir (SB, 2015). Bu araştırmada YBÜ'nin OKS açısından veriler incelendiğinde ise, 2017 yllında yoğun bakımlarda ortalama kalış süresi 5,96 gün iken, 2018 yılında ise 6,31 güne çıktığ tespit edilmiştir. Dâhili yoğun bakım ortalama kalış süresi 2017 yılında 4,74 gün iken 2018 yılında 5,10 gündür. Cerrahi yoğun bakım ortalama kalış süresi yıllara göre sirasılyla 4,37(2017) gün ve 4,60 (2018) gün olarak saptanmıştır. Yoğun bakım araştırma raporu (2015) verileri ile kıyaslandığında her iki yılda da OKS Türkiye ortalamasının altındadır. Literatür incelendiğinde iki farklı çalısmada karma yoğun bakımlarda ortalama kalıs süreleri 9,16 gün ve 10,2 gün olarak belirtilmiştir (Anushiravani ve Masoompour, 2017; Toptaş vd., 2018). Yapılan bir çalışmada (2018); üçüncü basamak karma YBÜ'nin ortalama yatış süresi 8,9 16 gün, yatak devir hızı 34,7, yatak doluluk oranı \%98,3 olarak gösterilmiştir (Efe, 2018). Araştırma sonuçları literatür sonuçları ile benzerlik göstermektedir.

Hastane yataklarının verimli kullanıldığını gösteren diğer bir gösterge de yatak devir hızıdır. YDH'nın düşük olması, hastanenin yatak kapasitesinin düşük ve ortalama yatış süresinin de kısa olduğunu gösterir, bu durumda birim maliyetlerin yüksek olmasına neden olur. Hastanenin büyüklüğü ile YDO ve YDH arasında bir ilişki vardır. Büyük hastaneler, tedavisi zor ve ağır hastalar kabul ettikleri için tedavi süresi uzamakta ve böylece yatak devir hızı düşmektedir (Yiğit ve Ağırbaş, 2004). Sözleşmeli yönetici performans 
kriterlerinde göre; sağlık tesislerinin yatak kapasitesinin doğru ve verimli kullanımını sağlamak için hastane YDH \%70-85 arasında olması gerekmektedir (SB, 2019). Tüm YBÜ'nin YDH oranlarındaki değişim incelendiğinde 2017 yılı ortalaması 69,98 iken, 2018 ortalamasının 80,68'e yükseldiği tespit edilmiştir. Yatak devir hızı; dâhili YBÜ’lerinde yıllara göre sırasıyla 56,48 (2017) ve 56,82 (2018) iken, cerrahi yoğun bakımda ise 83,92(2017) ve 80,49 (2018) olarak saptanmıştır. Literatürde yatak devir hız1, yataklı servisler için sık kullanılan bir kalite göstergesi olmakla birlikte YBÜ’ler için veri oldukça azdır. Anushiravani ve ark. tarafindan yapılan çalışmada, üçüncü basamak YBÜ’nin beş yıllık verileri incelenmiş, YDH 29,9-37,6 gün aralığında ve ortalama 34,38 gün olarak gösterilmiştir (Anushiravani ve Masoompour, 2017). Sözleşmeli yönetici performans kriterlerinde göre; tüm YBÜ'nin ortalama YDH 2017 yllinda hedef değerin altında iken 2018 yllında hedef değer sağlanmıştır.

Leblebici vd. (2019) tarafindan, İstanbul'da hizmet veren iki eğitim ve araştırma hastanesinin yeni doğan ve çocuk YBÜ performans düzeyleri PLM modeli değerlendirilmiştir. Araştırma sonucunda YBÜ; sirasiyla 2017 ve 2018 ylli; yatak doluluk oran1\%85,24-\%66,19, yatak devir hiz1 30,06 - 40,12 ve ortalama kalış gün sayıs1 10,6-10,1/gün ve PLM'de 4. bölgede yer aldığ1 bulunmuştur. Çocuk YBÜ performans değerlendirme sonuçlarına göre 4. bölgede yer almıştır. (Leblebici vd., 2019). Bu araştırmada çocuk YBÜ 2017 yllında 1. bölgede 2018 yılında ise ortalama yatış süresinin uzun, yatak devir hızının düşük olduğu ve yatak doluluk oranının yüksek olduğu 4. bölgede olduğu bulunmuştur. Yenidoğan YBÜ verileri, sirasıyla 2017 ve 2018 ylllarına göre; OKS 12,75-12,70 gün, YDO \%54,60-\%56,50, YDH 15,28-17,33 olarak tespit edilmiştir. PLM'de 2017 ve 2018 yllinda da 1. bölgede yer aldığ1; düşük YDO, düşük YDH ve OKS'nin uzun olduğu tespit edilmiştir. Bunun nedeninin yenidoğan YBÜ'nin ilin en fazla yatak kapasitesine sahip üçüncü basamak sağllk hizmeti vermesi ve sağllk hizmeti sunumunda rolü nedeniyle daha ciddi hastaları kabul etmesi olduğu söylenebilir. Bu durumun, ortalama kalış gün sayllarında diğer hastane türlerine göre anlamlı bir yüksekliğe sebep olduğu düşünülmektedir. Dolasıyla YDO ve YDH da düşmektedir.

PLM kullanılarak yapılan verimlilik analizinde, en verimli kabul edilen 3. bölgede yer alan yoğun bakımların sayısının 2017 yllında üç iken, 2018 yllında iki olduğu saptanmıştır. En verimsiz bölge olarak nitelendirilen 1. bölgede 2017 yllında üç yoğun bakım varken, 2018 yllında bu sayının ikiye düştüğü görülmektedir. Elde edilen verilere göre 2018 yılında 4. bölgede yer alan yoğun bakım sayısında artış olduğu saptanmıştır. 4. bölgede 2017 yılında bir YBÜ bulunurken 2018 yılında dört YBÜ yer almaktadır. PLM'de 4. bölge; yüksek YDO, düşük YDH ve uzun OKS olduğu bölgedir. 2018 y1lında bu bölgede yer alan YBÜ; Anestezi ve Reanimasyon YBÜ, Cerrahi YBÜ, Çocuk YBÜ, Nöroloji YBÜ’dir. Bu YBÜ’lerin 4. bölgede olmasının nedeni araştırıldığında; Nöroloji YBÜ’lerinde yatan hastaların genelde ileri yaşta ve immobil olması, mekanik ventilatör, monitör, idrar sondası gibi çok fazla invazif girişimlerin olması, ek risk faktörlerinde bulunması nedeniyle OKS süresinin uzun olabileceği bilinmektedir. Çetin vd. (2009) yapılan çalışmada Nörolji YBÜ ortalama kalış süresi 24.4+22.9 gün (2-114 arası) olduğu gösterilmiştir. (Çetin vd., 2009, s. 13). Anestezi ve Reanimasyon YBÜ, Cerrahi YBÜ, Çocuk YBÜ’lerini TSIM verileri incelendiğinde, 2017 yllında ventilatör doluluk oranları; YBÜ1 \%52,5, YBÜ2 \%45, YBÜ3 \%26,8'dir. 2018 yllında ventilatör dolulık oranları; YBÜ1 \%75,9, YBÜ2 \%71,1, YBÜ3’te \%53,9'dir. Bu veriler dikkate alındığında 2018 yılında ventilatör doluluk oranları daha yüksektir. Bu verilerden de anlaşılacağ1 gibi YBÜ’lerinde, daha komplike vakaların yattı̆̆, dolasıyla OKS uzun ve düşük YDH'nın olduğu söylenebilir. Kronik, ciddi vakaların takip edildiği üçüncü basamak YBÜ’rinde, tedavi komplikasyonları ve hastalı̆̆ın prognozu da OKS artışına neden olmaktadır. YDH'nın düşük olması, hastanenin yatak kapasitesinin düşük ve ortalama yatış süresinin de kısa olduğunu göstermektedir, bu durum da birim maliyetlerin yüksek olmasına neden olmaktadır. Hastanenin büyüklüğ̈ ile YDO ve YDH arasında bir ilişki vardır. Hastane büyüklüğü ile YDO ve YDH arasında bir ilişki vardır; büyük ölçekli hastanelerde, komplike hastaların tedavi sürdürüldügünden YDO oranı artarken YDH azalmaktadır (Yigit ve Ağırbaş 2004). Bu araştırmanın yapıldığı hastanede, ara YBÜ'leri ve palyatif bakım ünitesi olmadığından OKS'nin uzamasına neden olduğu düşünülmektedir.

Günümüzde hastaneler, sürdürülebilirliğini sağlayabilmek için mevcut kaynaklarını verimli kullanmak zorundadır. Özellikle hastanelerde sağlık harcamalarının önemli bir kısmını kullanan yoğun bakımların mevcut kaynaklarının optimum düzeyde kullanarak sağlık hizmeti sunması gerekmektedir. Kaynakların etkin kullanılabilmesi için ise hastanelerin tüm süreçlerinin kontrol altına alınarak bilimsel düzeyde performanslarının izlenmesi gerekmektedir. Hastane veya kliniklerin yatak kullanım performansının değerlendirilmesinde sıklıkla PLM kullanılmıştır. Hastane kliniklerine ait verilerin değerlendirilmesinde kullanım kolaylığı, kullanılan göstergelerin (yatak doluluk oranı, yatak devir hızı ve ortalama kalıss süresi) erişilebilir olması ve aynı anda anlamlı sonuç gösterebilmesi nedeniyle PLM tercih edilen bir değerlendirme 
yöntemidir. Hastane yöneticilerine yatak kullanım durumları konusunda yardımcı olabilecek bu metodun anlaşılması ve uygulanması önemli katkı sağlayacaktır. Bu araştırmada yoğun bakım üniteleri yatak kullanım performanslarının, Türkiye ortalamasına yakın değerlere sahip olduğu görülmüştür. Türkiye’de uygulama örneği henüz az sayıda bulunan PLM'nin kolay uygulanabilirliği, sağlkklı verilere dayanması, anlamlı ve iyileştirilebilir sonuçlar vermesi nedeniyle yıllar içinde daha sık kullanılacağı öngörülmektedir.

Gelecek çalışmalarda; hastane, klinikler ve yoğun bakım ünitelerinin yatak performans değerlendirilmesinde; hastane hizmet rol grupları da dikkate alınarak PLM'nin kullanılması önerilmektedir.

\section{Etik Beyan}

"Yoğun Bakım Yatak Kullanım Etkinliğinin Pabon Lasso Modeli İle Değerlendirilmesi”" başlıklı çalışmanın yazım sürecinde bilimsel, etik ve alıntı kurallarına uyulmuş; toplanan veriler üzerinde herhangi bir tahrifat yapılmamış ve bu çalışma herhangi başka bir akademik yayın ortamına değerlendirme için gönderilmemiştir. $\mathrm{Bu}$ araştırmada hazır veri seti kullanıldığı için etik kurul kararı zorunluluğu taşımamaktadır.

\section{Kaynakça}

Aeenparast, A., Farzadi, F., Maftoon, F., Zandian, H. ve Yazdeli, M. R. (2015). Quality of hospital bed performance studies based on pabon lasso model. International Journal of Hospital Research, 4(3), 143-148.

Ağırbaş, İ. (2019). Hastane yönetimi ve organizasyon. Ankara: Siyasal Kitapevi.

Aksaraylı, M., Kıdak, L. B. ve Güneş, M. (2009). Sağlık İşletmelerinde yatak kullanım etkinliğinin benzetim yoluyla optimizasyonu: Bir eğitim ve araşstırma hastanesi uygulaması. Gazi Üniveristesi İktisadi ve İdari Bilimler Fakeilltesi Dergisi, 1(11), 1-22.

Anushiravani, A. ve Masoompour, S M. (2017). Assessing the Performance of a medical intensive care unit: A 5 Year single-center experience. Indian Journal of Critical Care Medicine, 21(3), 163-166.

Arslan, E., Önder, N. T., Kayalı, S., Keskin, Z. ve Yiğit, Ö. (2015). Kamu hastanelerinde branş bazında hasta başı maliyet analizi (İstanbul Eğitim ve araştırma hastanesi örneği). Sağhle. Akademisyenleri Dergisis, 2(1, 40-52.

Azreena, E., Juni, M. H. ve Rosliza, A. M. (2018). A systematic review of hospital inputs and outputs in measuring technical efficiency using data envelopment analysis. International Journal of Health and Clinical Sciences, 5(1), 17-35.

Bahadori, M., Sadeghifar, J. M., Hamouzadeh, Hakimzadeh, P. ve Nejati, S. M. (2011). Combining multiple indicators to assess hospital performance in Iran using the pabon lasso model. Australasian Medical Journal, 4(4), 175-179.

Beylik, U. ve Pekcan, Y. A. (2008). Eğitim araștırma hastanelerinde etkinlik analizleri ve değerlendirilmesi. Sağhlkta Performns ve Kalite Dergisi, 3, 119-156.

Boz, C., Yilmaz, F. ve Şenel, İ. K. (2018). Effective Factors on bed operating performance of public hospitals association. Ombudsman Akademik, 5(9), 203-221.

Caballer-tarazona, M., Moya-clemente, I., Vivas-consuelo, D. ve Barrachina-martínez, I. (2010). A model to Measure the efficiency of hospital performance. Mathematical and Computer Modelling, 52(7-8), 1095-1102.

Çakmak, M., Öktem, M. K. ve Ömürgönülşen, U. (2009). Türk kamu hastanelerinde teknik verimlilik sorunu: Veri zarflama analizi tekniği ile sağlı bakanlı̆̆ı'na bağlı kadın doğum hastanelerinin teknik verimliliklerinin ölçülmesi. Hacettepe Sağhlk İdaresi Dergisi, 12(1), 1-36.

Çalıskan, Z. (2016). Kamu Hasta birlikleri performansının Pabón Lasso Modeli ile analizi. Sosyal Guvenlik Užmanlar Derneği Sosyal Güvence Dergisi, 5(10), 1-24.

Çetin, E. S., Aynalı, A., Demirci, S., Aşçı, S. ve Arıdoğan, B. C. (2009). Nöroloji yoğun bakım ünitesinde yatan hastalardan izole edilen hastane infeksiyonu etkenleri. Ankara Üniversitesi Tep Fakültesi Mecmuasi, 62(1), 13-17.

Choi, N. H. ve Jung, K. (2017). Measuring Efficiency and effectiveness of highway management in sustainability. Sustainability (Switzerland), 9(8), 1-15.

Cooper, G. S., Sirio, C. A., Rotondi, A. J., Shepardson, L. B. ve Rosenthal, G. E. (2016). Are readmissions to the Intensive care unit a useful measure of hospital performance? Medical Care, 37(4), 399-408.

Davoud, A., Mohammad, P., Issac, B., Hossein, A., Sadeghi, G. ve Salarikhah, E. (2014). Contemporary use of hospital efficiency indicators to evaluate hospital performance using the pabon lasso model. European Journal of Business and Social Sciences, 3(2), 1-8.

Efe, S. (2018). Üçüncü basamak karma bir yoğun bakım ünitesinde kalite göstergelerinin retrospektif değerlendirilmesi. Yoğun Bakım Dergisi, 9(1), 1-6.

Ekiyor, A. (2015). Evaluating Performance of chest diseases departments using hospital efficiency indicators in Turkey. British Journal of Economics, Management Trade, 6(2), 145-150.

Emamgholipour, S., Afkar A., Eskandari M. ve Tavakkoli, M. (2015). Performance evaluation of the effect of additive metformin to progesterone on patients a 5-year assessment with endometrial. International Journal of Hospital Research, 4(4), 177-188.

Evans, D. B., Edejer, T. T. T. J., Lauer, J., Frenk, J. ve Murray, C. J. L. (2001). Measuring quality: From the system to the provider. International Journal for Quality in Health Care, 13(6), 439-446. 
Gollhofer, R. E. (2015). Measuring the impact of process improvement programs on the performance of hospitals in mid-atlantic region using data envelopment analysis (Doktora Tezi). Capella University, İşletme Yönetimi.

Gree, L.V. (2002). How Many hospital beds? Sage Publications, 39(4), 400-412.

Güzel, A. (1996). Kapasite kullanım oranlar: Ankara rehabilitasyon merkezinde kapasite kullanmm oranlarmm analizi ve etki eden faktörlerin tespitine yönelik bir model (Yüksek Lisans Tezi). Hacettepe Üniveristesi, Sağllk Bilimleri Enstitüsü, Ankara.

Harper, P. R. ve Shahani, A. K. (2002). Modelling for the planning and management of bed capacities in hospitals. Journal of the Operational Research Society, 53(1), 11-18.

Keegan, A. D. (2010). Hospital bed occupancy: More than queuing for a bed. MJA, 193(5), 291-293.

Khalifa, M. ve Khalid, P. (2015). Developing strategic health care key performance indicators: a case study on a tertiary care hospital. Procedia Computer Science, 63(Icth), 459-466.

Lasso, H. P. (1986). Evaluating hospital performance through simultaneous application of several indicators. Bulletin Of The Pan American Health Organization, 20(4), 341-357.

Leblebici, Y., Çerçi, S., Bülbül, A., Uslu, H. S., Al, E. S. ve Selamaz, M. (2019). Yenidoğan yoğun bakım kliniğinde hizmet süreçlerinin değerlendirilmesi: Pabon Lasso metodu. 7. Cocuk Dostlar Kongresi. In, İstanbul, 351.

Linna, M., Häkkinen, U. ve Magnussen, J. (2006). Comparing hospital cost efficiency between Norway and Finland. Health Policy, 77, 268-278.

Özcan, Y. A. (2009). Quantitative methods in health care management: Techniques and applications.San Francisco: Jossey-Bas.

Özkan, B., Başligil, H. ve Şahin, N. (2011). Supplier selection using analytic hierarchy process: An application from Turkey." Proceedings of the World Congress on Engineering, II, 4-9. https://pdfs.semanticscholar.org/1655/3d5616899bcdae525e9f443d167047e25a9f.pdf

Rahman, H., Tumpa, T. J., Ali, S. M. ve Kumar, S. (2018). A grey approach to predicting healthcare performance. Measurement, 1-48. https://doi.org/10.1016/j.measurement.2018.10.055.

Sağlık Bakanlı̆̆ı (SB). (2015). Yoğun bakım üniteleri araştırması istatistik, analiz ve raporlama daire başkanlğ̆. Ankara: T.C. Sağlık Bakanlığı.

Sağlık Bakanlığı (SB). SAS. (2015). Sağllkta akereditasyon standartlar. Ankara: T.C. Sağlık Bakanlığı.

Sağlık Bakanlı̆̆1 (SB). (2016). Sağhlk istatistikleri ynllı̆̆. Ankara: T.C. Sağlık Bakanlığı.

Kamu Hastaneleri Istatistik. Raporu. (2017). Hastaneleri genel müdürlügü, istatistik, analiæ, raporlama ve stratejik yönetim dairesi başkanlĭg. Kamu Hastaneleri Genel Müdürlügü.

Sağlık Bakanlığ1 (SB). (2019). “yhgm.Saglik.Gov.Tr/TR,50846/Sozlesmeli-Yonetici-Performans-DegerlendirmeKriterleri-Gosterge-Kartlari.Html."

Sümbüloğlu, K. (1990). Sağhk Alanına Özel İstatistiksel Yöntemler. 3. Bask1. Ankara: Hatipoğlu Yayınlar1.

Tengilimoğlu, D., Işık, O. ve Akbolat, M. (2012). Sağhlk işletmeleri yönetimi. Ankara: Siyasal Kitapevi.

Türkiye Kamu Hastaneleri Kurumu (TKHK). (2016). Verimlilik Karne Uygulaması Gösterge Kartlar RV-05-2. İzleme, Ölçme ve Değerlendirme Kurum Başkan Yardımcılığı Verimlilik ve Kalite Yönetimi Daire Başkanlığı.

Toptas, M., Samanci, N. S., Akkoc, Yucetas, E., Cebeci, E., Sen, O., Can, M M. ve Ozturk, S. (2018). Factors affecting the length of stay in the intensive care unit: Our clinical experience. BioMed Research International, 1-4.

Tripathi, C. B., Kumar, R., Sharma, R. C. ve Agarwal, R. (2016). Assessment of performance of services in a tertiary care neuropsychiatric institute using Pabon Lasso model. Asian Journal of Medical, 7(6), 69-74.

TUİK (2017). TUIKK Sağlık Harcamaları.” http:// tuik.gov.tr/PreTablo.do?alt_id=1084 (April 20, 2019).

Veer, S van der., Vos, MLG de., Jager, KJ., Voort, PHJvan der., Peek, N., Westert, GP., Graafmans,

Vella, V., Aylin, P. P., Moore, L. K., Alice, N., Nichola, R. B, Gabriel, J. C. B., Lishman, H. ve Holmes, A. (2017). Bed utilisation and increased risk of clostridium difficile infections in acute hospitals in England in 2013/2014. BMJ Quality \& Safety, 26(6), 460-465.

Yiğit, V. ve Ağırbaş, İ. (2004). Hastane işletmelerinde kapasite kullanım oranının maliyetlere etkisi: Sağlık bakanlığı tokat doğum ve çocuk bakımevi hastanesinde bir uygulama. Hacettepe Sağllk İdaresi Dergisi 7(2), 141-162.

Yiğit, V. ve Esen, H. (2017). Pabon Lasso modeli ve veri zarflama analizi 1le hastanelerde performans ölçümü. Süleyman Demirel Üniversitesi Sağhk Bilimleri Dergisi, 8(2), 26-32.

Yiğit, P. ve Kumru, S. (2016). Türkiye'de hastane verimliliğinin pabon lasso modeli yöntemi ile incelenmesi. 10. Sağhlk Ve Hastane İdaresi Kongresi Sözel Bildiri Kitabı, Ankara, 206-7.

Yiğit, A. (2019). Türkiye'de hastane verimliliğinin meta analiz yöntemiyle tespit edilmesine yönelik bir araştırma. 2. Uluslararası Sağllk Bilimleri ve Yaşam Kongresi, Bildiri Sunum Notlar, 24-27 Nisan, Burdur. 2. Uluslararası Sağlık Bilimleri ve Yaşam Kongresi, Bildiri Sunum Notları, 24-27 Nisan,.

Yiğit, V. (2017). Türkiye'de üniversite hastanelerinde performansa dayalı ek ödeme sistemi. Journal of Contemporary Medicine, 7(2), 1-1.

Yıldız, M. S. (2017). Hastane yatak kullanım verimliliğinin değerlendirmesinde pabon lasso metodu: Literatür taraması. Uluslararası Sağllk Yönetetimi ve Stratejileri Araștırma Dergisi, 3(1), 152-163.

\section{EXTENDED ABSTRACT}

The health services provided in hospitals constitute the most important part of the health systems. This service provision has increasingly important cost inputs. In some countries, hospital expenditures make up more than half of the total health care. It is very important to use resources efficiently by 
performing performance measurements, particularly in public health institutions. In this context, hospitals should reduce their costs and provide quality health services in order to be efficient. Approximately $50 \%$ of the expenditure incurred by the health sector in Turkey is carried out by hospitals. Therefore, it is crucial to carry out performance and efficiency analyzes in hospitals. Different methods are used in performance evaluation in health institutions. These methods are usually ratio analysis, parametric and non-parametric methods. In addition, Pabon Lasso Model is frequently used in the evaluation of hospital bed capacity usage. This model was developed by Hipolito Pabón Lasso (1986) to be used to determine the relative performance of hospitals. In the performance measurement, bed occupancy rate (BOR), average length of stay (ALS) and bed turnover (BTR) indicators are used.

This study was aimed to analyze the bed usage performances of intensive care units operating in a training and research hospital in 2017 and 2018 with Pabon Lasso Model. Research data were taken from Primary Health Statistics Module. Written permission was obtained from the hospital management. MS Excel and Macromedia software were used for data analysis. Data analysis was performed using descriptive statistical methods.

As a result of the findings of the study, it was determined that the bed occupancy rate, bed turnover rate and average stay times of the intensive care units increased in 2018 compared to 2017. The average of the intensive care units in the Training and Research Hospital in 2017 BOR was 74.10\%, ALS was 5.99 days and BTR was 69.98. When the data of 2018 are examined, it is seen that the average BOR was $82.04 \%$, ALS is 6.31 days and BTR is 80.68. Intensive care unit with the highest value in terms of ICU in 2017: surgical ICU $(98.80 \%)$, ICU with the lowest value: general1 ICU $(50.70 \%)$. ALS has the highest value in terms of performance indicator; neurology $\operatorname{ICU}(15,29$ days), lowest value cardiovascular surgery intensive care ICU (2, 03 days). It has the highest value in terms of BTR indicator; coronary ICU (148.95), the newborn with the lowest value was found to be $\operatorname{ICU}(15,28)$. Intensive care unit with the highest value in surgical ICU $(99.60 \%)$ in 2018. The lowest value in neonatal ICU $(56.50 \%)$, ALS has the highest value in terms of performance indicator neurology ICU (17.21 days), lowest value; cardiovascular surgery ICU (1, 74 days). It has the highest value in terms of BTR indicator coronary ICU (139.75), the lowest value; neonatal ICU $(17,33)$ was determined. The average length of stay in both intensive care units is similar.

In the third region, which is productive area according to PLM in 2017; ICU1, ICU2, ICU7 were determined. According to PLM, 30\% of intensive care units were found to be completely efficient. Intensive care units with low bed occupancy rate, low bed turnover rate and long patient stay are considered inefficient. In this context, in the first inefficient area are ICU3, ICU5 and ICU10. According to PLM, 30\% of intensive care units were found to be completely inefficient. There are other intensive care units with high bed occupancy rate, low bed turnover rate and long-stay patient. In this context, these intensive care units in the second and fourth regions, which are efficient, but inefficient according to the model, but which are close to the average, make up $40 \%$ of the sample. These intensive care units will be efficient when the hospital managers transfer these intensive care units from the second and fourth regions to the third regions. According to the Pabon Lasso Model, in the third region where the performance of intensive care units in 2018 is productive according to the current bed average; ICU4 and ICU7 were determined. According to PLM, 20\% of intensive care units were found to be completely efficient. In the first region which is inefficient; ICU5 and ICU10 were determined. According to PLM, $20 \%$ of ICUs were found to be completely inefficient. Other intensive care units in the second and fourth regions, which are efficient, but inefficient according to the model, but which are close to the average, constitute $60 \%$ of the sample. In both years, it was found that some intensive care units performed poorly in terms of at least one of the performance indicators used as variables in the model.

When hospital managers transfer these intensive care units from the second and fourth regions to the third regions, these intensive care units will be more efficient. Intensive care units, which use a significant portion of the health expenditures in hospitals, should provide health services by using the available resources at the optimum level. In order to use resources efficiently, all processes of hospitals should be controlled and their performance at scientific level should be monitored. PLM has often been used to evaluate the performance of bed use in hospitals or clinics. The ease of use of PLM and the fact that the indicators within the scope of evaluation (bed occupancy rate, bed turnover rate and average residence time) are easily accessible and can show meaningful results at the same time will give favorable results in the evaluation of the data of hospital clinics. For this reason, it is important to understand and apply the 
method that can help hospital managers about bed use situations. According to the results of this study conducted to investigate the bed use performances of intensive care units serving in a training and research hospital, it can be said that bed efficiency is quite good. It is foreseen that this method, which has few application examples in our country, will be used more frequently in years because of its ease of applicability, based on healthy data, and providing meaningful and improvable results. 